\title{
A Novel Homeobox-Like Gene Associated with Reaction to Stripe Rust and Powdery Mildew in Common Wheat
}

\author{
D. Liu, X.-C. Xia, Z.-H. He, and S.-C. Xu
}

First, second, and third authors: Institute of Crop Science, National Wheat Improvement Center/The National Key Facility for Crop Gene Resources and Genetic Improvement, Chinese Academy of Agricultural Sciences (CAAS), 12 Zhongguancun South Street, Beijing 100081, China; third author: International Maize and Wheat Improvement Center (CIMMYT) China Office, c/o CAAS,Zhongguancun South Street, Beijing 100081, China; and fourth author: Institute of Plant Protection, Chinese Academy of Agricultural Sciences (CAAS), 2 Yuanmingyuan West Road, 100094 Beijing, China.

Accepted for publication 1 August 2008.

\section{ABSTRACT}

Liu, D., Xia, X.-C., He, Z.-H., and Xu, S.-C. 2008. A novel homeoboxlike gene associated with reaction to stripe rust and powdery mildew in common wheat. Phytopathology 98:1291-1296.

Stripe rust and powdery mildew, caused by Puccinia striiformis f. sp. tritici and Blumeria graminis f. sp. tritici, respectively, are severe diseases in wheat (Triticum aestivum) worldwide. In our study, differential amplification of a 201-bp cDNA fragment was obtained in a cDNA-amplified fragment length polymorphism (AFLP) analysis between near-isogenic lines $Y$ r1ONIL and Avocet S, inoculated with $P$. striiformis f. sp. tritici race CYR29. A full-length cDNA (1,357 bp) of a homeobox-like gene, TaHLRG (GenBank accession no. EU385606), was obtained in common wheat based on the sequence of GenBank accession AW448633 with high similarity to the above fragment. The genomic
DNA sequence $(2,396 \mathrm{bp})$ of TaHLRG contains three exons and two introns. TaHLRG appeared to be a novel homeobox-like gene, encoding a protein with a predicted 66-amino-acid homeobox domain. It was involved in race-specific responses to stripe rust in real-time quantitative polymerase chain reaction (PCR) analyses with $\mathrm{Yr}$ 9NIL, $\mathrm{Yr} 10 \mathrm{NIL}$, and Avocet S. It was also associated with adult-plant resistance to stripe rust and powdery mildew based on the field trials of doubled haploid lines derived from the cross Bainong 64/Jingshuang 16 and two $\mathrm{F}_{2: 3}$ populations from the crosses Lumai 21/Jingshuang 16 and Strampelli/Huixianhong. A functional marker, THRl was developed based on the sequence of TaHLRG and located on chromosome 6A using a set of Chinese Spring nulli-tetrasomic lines.

Additional keywords: durable resistance.
Stripe rust and powdery mildew, caused by Puccinia striiformis f. sp. tritici and Blumeria graminis f. sp. tritici, respectively, are serious wheat diseases worldwide, resulting in both yield losses and downgrading in quality (37). Use of resistant cultivars is the most economical and environmentally sound method to control these diseases. Disease resistance in crop plants has been generally characterized as race-specific resistance and non-racespecific or adult-plant resistance (APR) (14). Race-specific resistance is often overcome by new pathogen races. In contrast, APR is often long-lived under field conditions and is therefore preferred by breeders aiming to achieve durable resistance, and has been emphasized to increase crop resistance in breeding (37). For example, the wheat cultivar Knox and its derivative Massey showed stable and effective resistance against powdery mildew for 20 years (9). Forty-four stripe rust resistance and 49 powdery mildew resistance genes in wheat have been formally catalogued $(17,26-28,30,33)$. Some of them were transferred from wild relatives. A considerable number of them $(\mathrm{Yr} 11, \mathrm{Yr} 12, \mathrm{Yr} 13, \mathrm{Yr} 14$, Yr16, Yr18, Yr29, Yr30, Yr31, Yr36, and Yr39) confer APR to stripe rust and two (Pm38 and Pm39) provide APR to powdery mildew $(18,19,21,28)$.

Previous studies indicated that APR genes involved in resistance to different diseases are clustered together on wheat chromosomes $(35,39,41)$. For example, Yrl8, Lr34, and Pm38

Corresponding authors: X.-C. Xia and Z.-H. He

E-mail addresses: xiaxianchun@ caas.net.cn or zhhe@public3.bta.net.cn

doi:10.1094/PHYTO-98-12-1291

(C) 2008 The American Phytopathological Society were located on the same position of chromosome 7DS conferring resistance to stripe rust, leaf rust, and powdery mildew, respectively. They were also associated with leaf tip necrosis (Ltn) (28,37,41). Similarly, Yr29, Lr46, and Pm39, which are associated with leaf tip necrosis, were mapped to the same location of chromosome $1 \mathrm{BL}$ and co-localize with genes encoding $\beta 1$-proteasome subunits (35). The association of APR genes is likely due to close linkage or the pleiotropic effects of a single locus for resistance to different diseases. However, few resistance genes have been cloned in wheat and none is of the APR type.

Many resistance genes contain conserved nucleotide-binding domains (31). Homeobox genes encode DNA-binding domains with a helix-turn-helix structure, many of which are involved in gene regulation (8). Typical homeodomains contain 60 amino acids and atypical domains have more or fewer amino acids $(4,8)$. In plants, homeobox proteins are divided into several families, such as Knox, WOX, Hd-Zip, PHD-finger, GLABRA-, and BEL1-like proteins, according to sequence conservation within the homeodomain and adjacent regions $(5,11,12,20,23,34)$. Most homeobox genes participate in plant development processes $(4,5,7,8)$. Some plant HD-Zip genes regulate a biochemical pathway for drought stress (1), and H52 from tomato encoding a distinct HD-Zip protein was involved in cellular protection from programmed cell death (25). OCP3 in Arabidopsis mediates resistance to infection by necrotrophic pathogens (6). Here we report a novel homeobox-like gene in common wheat, designated TaHLRG, which is associated with race-specific reaction to stripe rust and APR to both stripe rust and powdery mildew. The role of TaHLRG for resistance to wheat disease will be discussed. 


\section{MATERIALS AND METHODS}

Plant materials. The near-isogenic lines $Y r 9 / 6 *$ Avocet $\mathrm{S}$ (Yr9NIL), Yr10/6*Avocet S (Yr10NIL), and Avocet S, kindly provided by C. R. Wellings, Plant Breeding Institute Cobbitty, University of Sydney, Australia, were used for stripe rust tests in the greenhouse, cDNA-amplified fragment length polymorphism (AFLP) assay, and cloning of the homeobox-like gene. Chinese Spring nulli-tetrasomic (NT) lines used for determining the location of the homeobox-like gene were provided by R. A. McIntosh, University of Sydney. A doubled haploid (DH) population (128 lines) derived from the cross Bainong 64/Jingshuang 16 and two $F_{2: 3}$ populations from the crosses Lumai 21/ Jingshuang 16 (186 lines) and Strampelli/Huixianhong (226 lines) were used for the assessment of APR to stripe rust and powdery mildew in the field. Strampelli was introduced from Italy and showed good APR to stripe rust in China for the last 35 years, whereas Huixianhong is highly susceptible to all Chinese $P$. striiformis f. sp. tritici races. Bainong 64 and Lumai 21 were previous leading Chinese wheat cultivars with good APR to powdery mildew, whereas Jingshuang 16 is highly susceptible to current $B$. graminis f. sp. tritici races in China. The $\mathrm{F}_{2: 3}$ lines generated from $\mathrm{F}_{2}$ plants were planted and harvested as bulks with over 50 plants of each line to produce $F_{2: 3}$ populations that can be maintained as bulk populations, each deriving from a single $\mathrm{F}_{2}$ plant.

Inoculation of $\boldsymbol{P}$. striiformis f. sp. tritici. The $\operatorname{Yr} 9 \mathrm{NIL}$, Yr10NIL, and Avocet $\mathrm{S}$ were inoculated with two P. striiformis $\mathrm{f}$. sp. tritici races, CYR29, and/or culture 78028. Yr9NIL was susceptible to CYR29 and resistant to 78028, whereas Yr10 was resistant, and Avocet $\mathrm{S}$ was susceptible to both isolates. Wheat seedlings were grown in a growth chamber at $17^{\circ} \mathrm{C}$ with $50 \%$ relative humidity $(\mathrm{RH})$, and inoculated with $P$. striiformis $\mathrm{f}$. $\mathrm{sp}$. tritici urediospores on the first fully expanded leaves as described by Stubbs (40) and Sun et al. (42). After the inoculation, the seedlings were maintained in the dark at 9 to $11^{\circ} \mathrm{C}$ with $100 \%$ $\mathrm{RH}$. As a control, wheat seedlings were mock-inoculated with water and taken through the same process. Inoculated and corresponding mock-inoculated leaves for each treatment ( $\mathrm{r}$ 9-CYR29, Yr9-78028, Yr10-CYR29, and Avocet-CYR29) were collected at $12,15,18,21,24,28,32$, and $36 \mathrm{~h}$ post-inoculation (hpi) for subsequent cDNA-AFLP and quantitative polymerase chain reaction (Q-PCR) analysis. Meanwhile, the seedlings of susceptible check cultivar Mingxian169 in each treatment were transferred into a growth chamber with identical conditions, i.e., the day/night regime of $14 \mathrm{~h}$ light $(28,000 \mathrm{~lx})$ at $17^{\circ} \mathrm{C}$ and $10 \mathrm{~h}$ of darkness at

TABLE 1. Oligonucleotides used for $3^{\prime}$ rapid amplification of cDNA ends (RACE), 5' RACE, reverse transcription-polymerase chain reaction (PCR), and PCR amplification of genomic DNA

\begin{tabular}{ll}
\hline Primer & \multicolumn{1}{c}{ Primer sequence $\left(5^{\prime}\right.$ - $\left.^{\prime}\right)$} \\
\hline $3^{\prime}$ AP1 & CTGATCTAGAGGTACCGGATCCTTTTTTTTTTTTTTT \\
3'AP2 & CTGATCTAGAGGTACCGGATCC \\
3'GSP1 & TGGACCCGAGGAGGATGAATGG \\
5'AP1 & GGCCACGCGTCGACTAGTACGGGIIGGGIIGGGIIG \\
5'AP2 & GGCCACGCGTCGACTAGTAC \\
5'GSP1 & TGGGGGCACCATCATCT \\
5'GSP2 & GAGCGGTCCGGGGAGGCGTGAA \\
5'GSP3 & CTTGGCGCCTGCCCCGTCATACTTGTC \\
OP1 & CAACGCCTCCCCGGACCGCTCC \\
OP2 & GAGATCCCCAGGAAGCACAGC \\
OP3 & GTAAGCTTCTCCTCCCACCCACCCCTCTCC \\
OP4 & TCTCCTCCCACCCACCCCTCTCCA \\
OP5 & CGGCCACTGGGGGCACCATCATCT \\
OP6 & CAGCGGCACCCTCTTACATC \\
OP7 & AGGCCCTCTATTTTGACGCTCGTGTTCT \\
OP8 & AAGCGCACAGGGAAGCGAAACAACT \\
Tub2U & TGTGCCCCGTGCTGTTCTTATG \\
Tub2L & CCCTTGGCCCAGTTGTTACCC \\
\hline
\end{tabular}

$12^{\circ} \mathrm{C}$, with $70 \%$ RH. All checks were fully susceptible $($ IT $=4)$ 2 weeks after inoculation, indicating a successful inoculation in all treatments.

cDNA-AFLP assay. Total RNA was prepared from the first leaves of CYR29-inoculated and corresponding mock-inoculated Yr10NIL and Avocet S, collected at five time points (15, 18, 21, 24, and 36 hpi) using TRIZOL reagent (Invitrogen, Carlsbad, CA) according to the manufacturer's recommendations. Dnase Itreated (Qiagen, Hilden, Germany) total RNA was then used as a template for double-stranded cDNA amplification by a doublestranded cDNA amplification kit (TaKaRa, Dalian, China) following the manufacturer's recommendations. The double-stranded cDNA was digested with restriction enzymes PstI and MseI (New England Biolabs, Ipswich, CT), and the $3^{\prime}$ regions were captured on streptavidin Dynabeads (Invitrogen, Carlsbad, CA). The preamplifications were performed with the Pst I and MseI primers, with either $\mathrm{T}$ or $\mathrm{C}$ as the $3^{\prime}$ nucleotide. From a 40-fold dilution of the pre-amplified samples, $5 \mu \mathrm{l}$ was used for the final selective amplifications using PstI and $M s e$ I primers with three selective nucleotides (CGA or TAC). Amplification products were separated on $5 \%$ polyacrylamide gels and visualized by silver staining (3). The differential PCR fragments amplified from the cDNAAFLP assay were cloned following the method described by $\mathrm{Xu}$ et al. (44).

Gene cloning by $3^{\prime}$ RACE, 5' RACE, and PCR amplification of genomic DNA. Oligonucleotides (Table 1) used for $3^{\prime}$ and 5' RACE were designed based on the sequence of a wheat EST (GenBank accession no. AW448633). This EST was detected in a BLAST search, and was highly similar to a 201-bp differential cDNA-AFLP fragment. DNase I-treated (Qiagen, Hilden, Germany) total RNA from seedlings of $\mathrm{Yr} 10 \mathrm{NIL}$ inoculated with CYR29 was used as a template for 3' and 5' rapid amplification of cDNA ends (RACE). For 3' RACE, an oligo-dT adapter primer (AP), 3'AP1, was used in RT-PCR for rapid amplification of the first-strand cDNA using an RT kit (Qiagen, Hilden, Germany) following the manufacturer's recommendations. A gene-specific primer (GSP), 3'GSP1, and an adapter primer, 3'AP2, permitted capture of $3^{\prime}$-mRNA sequence for the 563- to 1357-bp region. PCR was performed using LA Taq DNA polymerase (TaKaRa, Dalian, China) with an annealing temperature of $60^{\circ} \mathrm{C}$ according to the manufacturer's recommendation.

The $5^{\prime}$ end of the cDNA was amplified using the 5'-RACE technique following the manufacturer's instructions (Invitrogen, Carlsbad, CA). The primer 5'GSP1 was used to obtain the firststrand cDNA and a poly-C tail was added to the 3 ' end of the cDNA. In the second PCR, a cDNA fragment (1 to $286 \mathrm{bp}$ ) was amplified with the primer set $5^{\prime} \mathrm{GSP} 2 / 5^{\prime} \mathrm{AP} 1$ and sequenced. Then, 5'GSP3/5'AP2 were used in PCR amplification with the above 286-bp PCR product as template, and a 157-bp cDNA fragment ( 1 to $157 \mathrm{bp}$ ) was amplified. The two fragments overlapped by $157-b p$ with $100 \%$ sequence identity. The sequence of the 5'RACE fragment confirmed that the 286-bp cDNA fragment was the $5^{\prime}$-end sequence ( 1 to $286 \mathrm{bp}$ ) of TaHLRG. The primer set OP4/OP5 was designed from the AW448633 sequence to obtain a $380-\mathrm{bp}$ ( 8 to $387 \mathrm{bp}$ ) cDNA fragment that overlapped with the $5^{\prime}$-end sequence, with $100 \%$ sequence identity in $279 \mathrm{bp}$. The primer set OP1/OP2 was used to amplify the region 266 to $665 \mathrm{bp}$, overlapping with the OP4/OP5 amplification region and 3' RACE cDNA sequence in 122 and $103 \mathrm{bp}$, respectively, with $100 \%$ sequence identity. PCR was performed using $P f u$ DNA Polymerase (TIANGEN, Beijing, China) with an annealing temperature 55 to $65^{\circ} \mathrm{C}$ following the manufacturer's recommendation.

Genomic DNA was extracted from Yr10NIL seedlings (36). The genomic DNA sequence of the TaHLRG gene was assembled with PCR amplification of four primer sets (OP4/OP5, OP1/OP2, 3'GSP1/OP6, and OP7/OP8; Table 1), amplifying the regions covering 1 to 477,259 to 755,653 to 1985 , and 1,916 to $2,396 \mathrm{bp}$, 
respectively, with $100 \%$ identity in the overlapping sequences. PCR was performed using $P f u$ DNA Polymerase (TIANGEN, Beijing, China) with an annealing temperature of 55 to $65^{\circ} \mathrm{C}$ according to the manufacturer's recommendation.

Real-time quantitative PCR. Total RNA samples were extracted using TRIZOL reagent (Invitrogen, Carlsbad, CA) from the inoculated and corresponding mock-inoculated leaves of each treatment (Yr9-CYR29, $Y r 9-78028, Y r 10-C Y R 29$, and AvocetCYR29) at eight time points $(12,15,18,21,24,28,32$, and $36 \mathrm{hpi}$ ), following protocols recommended by the manufacturer. One-step RT-PCR (RT kit, Qiagen, Hilden, Germany) was performed using DNase I-treated (Qiagen, Hilden, Germany) total RNA as template.

In the Q-PCR assay, sequence-specific primer pairs, 3'GSP1/ OP6 and Tub2U/Tub2L designed by DNAStar, were used to quantify accumulation of TaHLRG transcripts and to normalize the amount of cDNA samples, respectively. Tub2U/Tub2L was an endogenous control from the sequence of the Triticum aestivum beta-tubulin 2 gene (GenBank accession U76745), amplifying a 135-bp fragment (176 to $310 \mathrm{bp}$ ). The cDNA region amplified with the primer set $3^{\prime}$ GSP1/OP6 was 201 bp (563 to $763 \mathrm{bp}$ ), whereas the corresponding genomic region included an intron (771 to 1,902 bp), facilitating a check of genomic DNA contamination in cDNA samples. All Q-PCR products from the two primer sets were sequenced to confirm the sequence identity with the template cDNA. Q-PCR experiments were performed in an ICycler iQ (Bio-Rad) with high amplification efficiency using a SYBR GREEN kit (Qiagen, Hilden, Germany) according to the manufacturer's recommendations.

The $2^{-\Delta \Delta \mathrm{C}}$ T method (22) was used to normalize and calibrate the TaHLRG $C_{\mathrm{T}}$ values relative to the beta-tubulin 2 endogenous control and the corresponding mock-inoculated controls. $C_{\mathrm{T}}$ values included in the analyses were based on three replicates for each treatment at each time point. All statistical analyses were performed using Optical System Software version 3.1.

Field trials for stripe rust and powdery mildew reactions. The $226 \mathrm{~F}_{2: 3}$ lines from cross Strampelli/Huixianhong were tested for stripe rust reaction in Qingshui following inoculation with $P$. striiformis f. sp. tritici race CYR32 in the 2004 to 2005, 2005 to 2006, and 2006 to 2007 cropping seasons. Qingshui, located in the Gansu province, is considered a stripe rust 'hot spot' in China, having ideal conditions for rust infection and spread. Field trials were conducted in a randomized complete block design with three replicates; each plot consisted of two $1.5-\mathrm{m}$ rows spaced $25 \mathrm{~cm}$ apart. Approximately 150 seeds were sown in each plot. The highly susceptible line Tiaogan 601 was used as a susceptible check and was planted after every 10 plots. Spreader rows of Tiaogan 601 were planted perpendicular and adjacent to the rows of tested lines. Stripe rust severities were assessed around 25 June for the first time and then at weekly intervals for two further weeks using the modified Cobb scale $(29,32)$.

The $128 \mathrm{DH}$ lines from cross Bainong 64/Jingshuang 16 and $186 \mathrm{~F}_{2: 3}$ lines from cross Lumai 21/Jingshuang 16 were tested in the field for powdery mildew reaction in Beijing and Anyang located in Henan province, during the 2004 to 2005 and 2005 to 2006 cropping seasons. In Beijing, they were artificially inoculated with the prevalent $B$. graminis f. sp. tritici isolate E20, whereas in Anyang a mixture of pathotypes was used. Field trials were planted in randomized complete block designs with three replicates; each plot was comprised of two 1.5-m rows spaced $25 \mathrm{~cm}$ apart. Approximately 150 seeds were sown in each plot. Spreader rows of the susceptible cultivar Jingshuang 16 surrounded the tested cultivars and were also planted after every 10 plots. In Beijing, the infection severity on F1 leaves (the leaf below the flag leaf) of 10 arbitrarily selected plants from each plot were scored, based on the actual percentage (0 to 100\%) leaf area covered by powdery mildew (10). Disease scoring was carried out for the first time 3 weeks after inoculation and then at weekly intervals until leaves were physiologically mature. Disease severities of 10 selected plants were averaged to obtain a mean severity for each line. In Anyang, powdery mildew severities on the F-1 leaf of each line were visually rated as percentage leaf area covered by powdery mildew, when the disease severities of the susceptible check cv. Jingshuang 16 reached a maximum level around 18 May 2005 and 2006. The maximum stripe rust and powdery mildew severity were used to analyze their association with TaHLRG gene.

A functional marker, THR1 was developed from the sequence of TaHLRG using the software SSRHunter1.3. One-way analysis of variance (ANOVA), using the software SAS 6.12, was conducted to determine the association between the functional marker THRI and APR reaction to powdery mildew and stripe rust.

\section{RESULTS}

Cloning a homeobox-like gene. In the cDNA-AFLP assay, 192 transcript derived fragments (TDF) were obtained and sequenced, ranging from 80 to $750 \mathrm{bp}$ in size. A 201-bp cDNA fragment was expressed at five time points $(15,18,21,24$, and 36 hpi) in $Y r 10$ NIL inoculated with $P$. striiformis f. sp. tritici race CYR29 and matched known genes involved in pathogen response. A wheat EST (GenBank accession no. AW448633) was detected through a BLAST search using the 201-bp cDNA sequence in a search against the wheat EST database in GenBank. Oligonucleotide primers were designed based on the AW448633 sequence, and a new Triticum aestivum homeobox-like resistance gene, designated TaHLRG, was cloned in YrlONIL by 3' RACE, 5' RACE, and PCR amplification of genomic DNA, encoding a protein with a predicted HOMEOBOX_2 domain. In the genomic clone the sequence was 2,396 bp (GenBank accession no. EU385606), with three exons from nucleotides 131 to 313,411 to 770 , and 1903 to 2373 . The assembled full-length cDNA sequence (GenBank accession no. EU364815) was 1,357 bp containing an open reading frame (ORF) of 1,014 bp. It encoded a protein of 337 amino acid residues with a predicted 66-aminoacid HOMEOBOX_2 domain (PS500071, at positions 11 to 76) close to the $\mathrm{N}$ terminus that formed a conserved helix-turn-helix structure including a first helix (amino acids 11 to 43), a turn (amino acids 44 to 55) and a second helix (amino acids 56 to 76) as predicted by ScanProsite. TaHLRG was compared with 20 known genes with HOMEOBOX_2 domain sequences (Fig. 1) in maize, Arabidopsis thaliana, barley (Hordeum vulgare L.), and rice (Oryza sativa L.), which contained the conserved residues in alignment of Swiss-Prot true positive hits by PS500071 and were chosen from their representative sequence homology in each gene family. The predicted homeobox of TaHLRG contained six conserved residues (Leu-39, Phe-43, Trp-65, Phe-66, Asn-68, and Arg-70) and six frequently occurring residues (Arg-25, 69, 75; Gln-61, 67; and Val-62). The other residues of TaHLRG were not homologous to any known homeodomain proteins, indicating that TaHLRG is a new homeobox-like gene.

Expression analysis of TaHLRG. In a Q-PCR assay, the transcript level of TaHLRG was up-regulated in the compatible ( $Y r 9-C Y R 29)$ interaction at $15 \mathrm{hpi}$ and no significant changes were found at seven other time points $(12,18,21,24,28,32$, and 36 hpi) (Fig. 2). In the incompatible interaction (Yr10-CYR29), the transcript level of TaHLRG was firstly down-regulated at $24 \mathrm{hpi}$ and then up-regulated at $28 \mathrm{hpi}$, respectively, and no significant changes were detected at six other time points (Fig. 2). These results indicated that TaHLRG was constitutively expressed in both inoculated and mock-inoculated samples, and might be involved in both compatible and incompatible race-specific responses.

TaHLRG was associated with adult-plant resistance to stripe rust and powdery mildew. A functional marker, THRI 


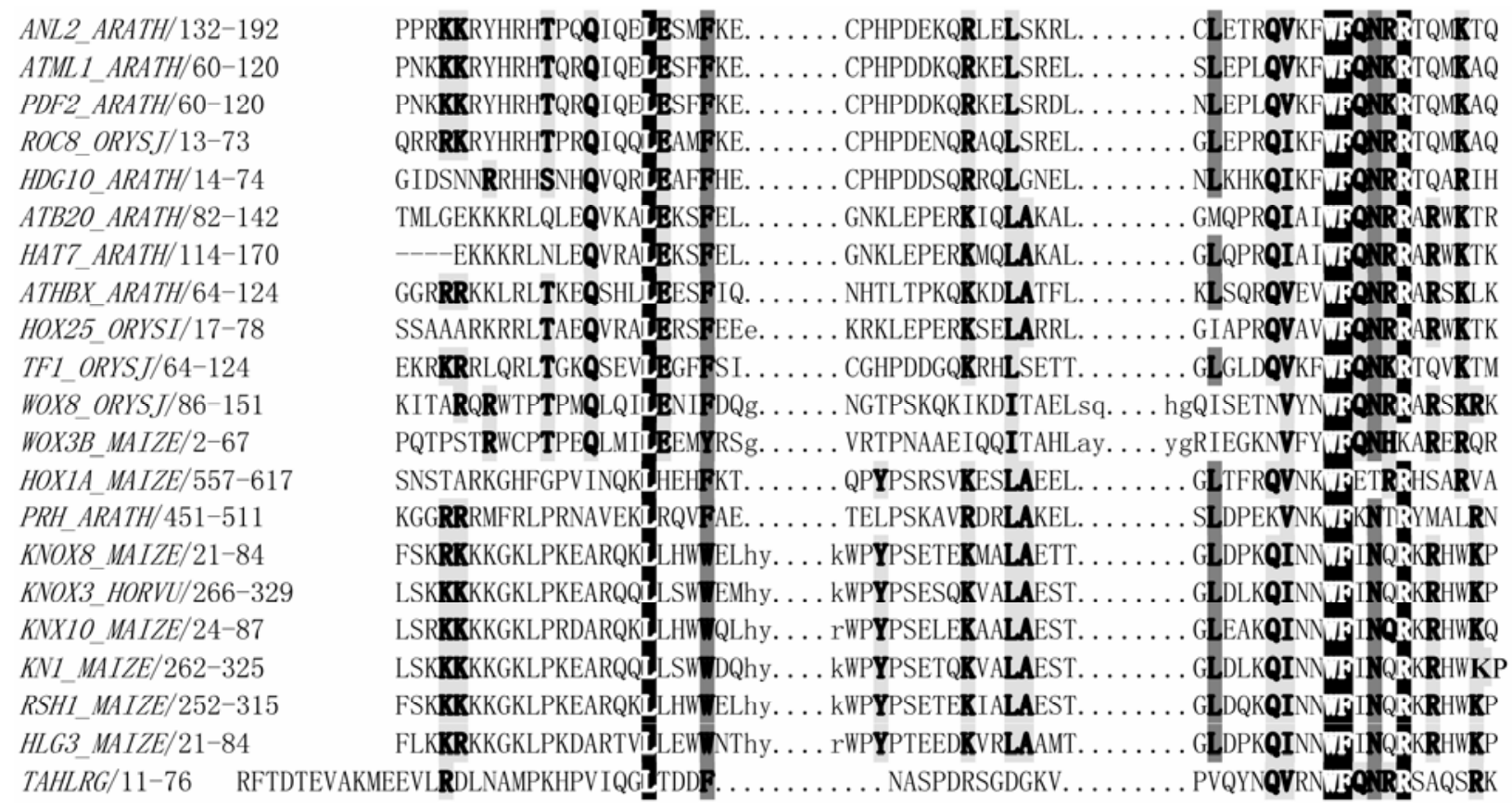

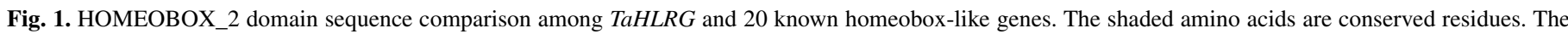
numbers following the gene names indicate the position of helix-turn-helix domain in the deduced peptides.

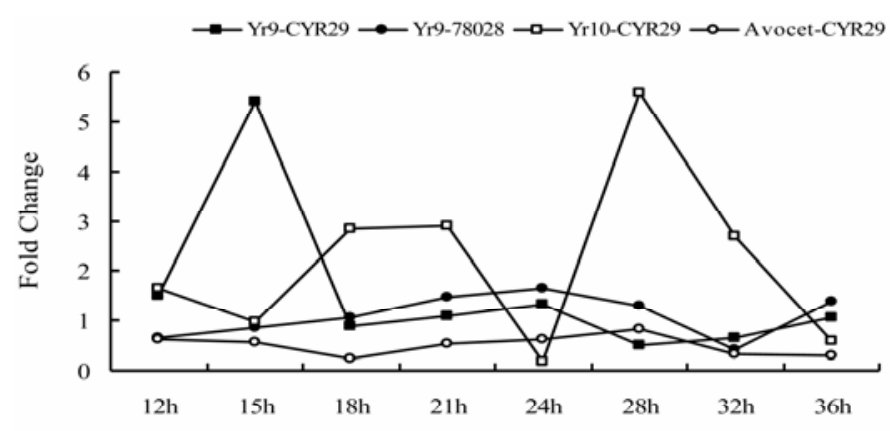

Hours postinoculation

Fig. 2. TaHLRG transcript levels relative to corresponding mock-inoculated samples at eight sampling points. Interactionas were $\mathrm{Yr}$ 9NIL-CYR29 (compatible), Yr9NIL-78028 (incompatible), Yr10NIL-CYR29 (incompatible), and Avocet-CYR29 (compatible).

(primer set OP3/5'GSP3), was developed from the sequence of TaHLRG, amplifying two PCR fragments of 145 and 157 bp in two parents of the populations, respectively. The sequence of the 157-bp PCR fragment is $100 \%$ identical to that of TaHLRG, whereas two simple sequence repeats were absent in the 145-bp PCR fragment.

THR1 was used to genotype three populations. One-way ANOVA indicated that the gene explained 9.3 to $9.7 \%$ and 11.9 to $20.5 \%$ of the phenotypic variance for powdery mildew reaction in populations Bainong 64/Jingshuang 16 and Lumai 21/Jingshuang 16 , respectively, and accounted for 11.8 to $22.5 \%$ of the phenotypic variance for stripe rust resistance in the population from Strampelli/Huixianhong across different environments (Table 2). The results indicated that TaHLRG was strongly associated with APR for both stripe rust and powdery mildew resistance in wheat.

Chromosomal location of TaHLRG. In PCR amplification with the marker THRI, no PCR product was amplified from the Chinese Spring (CS) nulli-tetrasomic (NT) lines N6A/T6B and N6A/T6D (Fig. 3). However, a 145-bp fragment was amplified from CS and all other NT lines (data not shown), indicating that TaHLRG was located on wheat chromosome 6A.

\section{DISCUSSION}

TaHLRG is a novel homeobox-like gene identified through a BLAST search against the $\mathrm{nr}$ database in GenBank. The specific motif, HOMEOBOX_2, contains 12 conserved residues, without a consensus pattern with other homeobox-like genes. Apart from the 12 conserved residues in the homeobox domain of TaHLRG (Fig. 1), other residues were not homologous to any known homeodomain proteins. Therefore, TaHLRG may encode a new homeobox protein.

A hypersensitive response (HR) is an efficient plant defense against biotrophic pathogens, resulting in localized cell death and formation of necrotic lesions. In incompatible interactions between resistant wheat cultivars and stripe rust races, the host cells start to become necrotic at $24 \mathrm{hpi}$ (16). At the same time, the structural defense reactions such as formation of cell wall apposition, collar or papillae are more pronounced in the infected leaves of the resistant cultivars than in those of the susceptible ones (15). After $24 \mathrm{hpi}$, the infected cells become necrotic and collapse inhibiting the proliferation of the stripe rust fungus (16). In the incompatible interaction (Yr10-CYR29), the expression of TaHLRG was detected in the above two phases. At the beginning of the structural defense reaction, $24 \mathrm{hpi}$, TaHLRG was downregulated (Fig. 2). TaHLRG was strongly up-regulated at $28 \mathrm{hpi}$, corresponding to a period of cell death, which may stop further development of pathogen. In contrast, no significant change of TaHLRG transcripts was found in the compatible interaction of Avocet-CYR29. This indicated that TaHLRG might play an important role in wheat line $\operatorname{Yr} 10 \mathrm{NIL}$ against stripe rust race CYR29. In the compatible interaction of $Y r 9$-CYR29, the transcript level of TaHLRG was strongly up-regulated as early as $15 \mathrm{hpi}$, before host cells became necrotic. In contrast, the expression of TaHLRG showed no significant changes among different time points in the incompatible interaction of $\operatorname{Yr} 9-78028$. These reactions may reflect the specific incompatible and compatible interactions between resistance gene and stripe rust races. A number of DNA-binding proteins are important in the transmission of defense signals for the plant-pathogen interaction to either activate or suppress downstream gene expression, and in the regulation of cross-talk between different signaling pathways $(2,24)$. TaHLRG has the characteristics of genes with a DNA-binding 
TABLE 2. One-way analysis of variance for the association between TaHLRG and adult-plant reaction to stripe rust and powdery mildew in three populations

\begin{tabular}{|c|c|c|c|c|c|}
\hline Population & Disease & Location & Cropping season & $R^{2 \mathrm{a}}$ & $P$ \\
\hline \multirow[t]{2}{*}{ Bainong 64/Jingshuang 16} & \multirow[t]{2}{*}{ Powdery mildew } & Beijing & 2004-05 & 9.3 & 0.0005 \\
\hline & & Anyang & 2004-05 & 9.7 & 0.0004 \\
\hline \multirow[t]{3}{*}{ Lumai 21/Jingshuang 16} & \multirow[t]{3}{*}{ Powdery mildew } & Beijing & 2004-05 & 20.5 & $<0.0001$ \\
\hline & & Beijing & $2005-06$ & 11.9 & $<0.0001$ \\
\hline & & Anyang & 2005-06 & 17.5 & $<0.0001$ \\
\hline \multirow[t]{3}{*}{ Strampelli/Huixianhong } & \multirow[t]{3}{*}{ Stripe rust } & Qingshui & 2004-05 & 11.8 & $<0.0001$ \\
\hline & & Qingshui & $2005-06$ & 22.5 & $<0.0001$ \\
\hline & & Qingshui & 2006-07 & 12.8 & $<0.0001$ \\
\hline
\end{tabular}

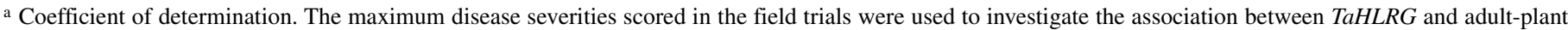
reaction to powdery mildew or stripe rust.

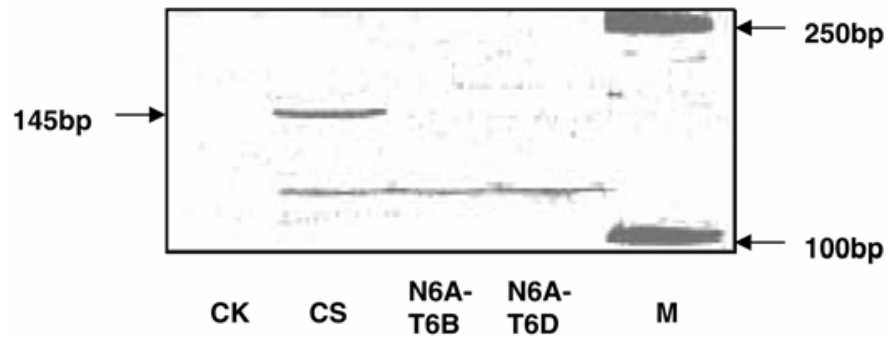

Fig. 3. Chromosomal location of TaHLRG by amplifying Chinese Spring (CS), N6A-T6B, and N6A-T6D with the marker THR1 and separating products on a 5\% denaturing polyacrylamide gel. M, DNA ladder DL2000 (TaKaRa, Dalian, China); CK, check with no template DNA in the PCR reaction; CS, Chinese Spring; N6A-T6B, nullisomic 6A-tetrasomic 6B; N6A-T6D, nullisomic $6 \mathrm{~A}$-tetrasomic $6 \mathrm{D}$

region. Possibly, TaHLRG is involved in cross-talk between different signaling pathways.

To date, three powdery mildew resistance genes (13) and five stripe rust resistance genes $(26,27,28)$ are located on chromosome 6 in wheat. Among them, Yr36-6BS was characterized as a hightemperature APR gene that was susceptible to 15 different stripe rust races at the seedling stage and resistant to PST100 and PST101 at the adult plant stage under high temperature. Pm11, Pm14, Pm31, Yr4a, Yr4b, Yr20, and Yr23 are major genes with specific resistance to different pathotypes. Yr35-6BS and Yr38-6A are dominant genes with resistance to a range of $P$. striiformis $\mathrm{f}$. sp. tritici pathotypes. Based on its location, TaHLRG may be a new quantitative trait locus (QTL) associated with resistance to both powdery mildew and stripe rust. In addition, the EST AW448633 showed high homology (93\%) to a wheat EST BG262981 on chromosomes 6A and 6B from a blast search of mapped wheat EST in the GrainGenes website, confirming the location of TaHLRG.

Previous studies indicated that APR genes against different pathogens are located on the same chromosomal regions and they may be involved in a similar biochemical pathway for APR in wheat $(18,35,38,39,41)$. The $\beta 1$ din subunit of the $20 \mathrm{~S}$ proteasome, located in the genomic intervals carrying Lr34/Yrl8/ Pm38/Ltn and Lr46/Yr29/Pm39/Ltn (35), was shown to be involved in the establishment of systemic acquired resistance (43). In our study, TaHLRG was characterized as a gene involved in race-specific responses. Highly significant associations between TaHLRG and stripe rust and powdery mildew resistance were found in three populations across two or three environments, indicating a stable effect associated with TaHLRG for resistance to stripe rust and powdery mildew.

\section{ACKNOWLEDGMENTS}

We thank R. A. McIntosh, the Plant Breeding Institute, and the University of Sydney for the critical review of this manuscript. This study was supported by the National Science Foundation of China (30471083).

\section{LITERATURE CITED}

1. Agalou, A., Purwantomo, S., Övernäs, E., Johannesson, H., Zhu, X., Estiati, A., Kam, R., Engström, P., Slamet-Loedin, I., Zhu, Z., Wang, M., Xiong, L., Meijer, A., and Ouwerkerk, P. 2008. A genome-wide survey of HD-Zip genes in rice and analysis of drought-responsive family members. Plant Mol. Biol. 66:87-103.

2. Anderson, J. P., Badruzsaufari, E., Schenk, P. M., Manners, J. M., Desmond, O. J., Ehlert, C., Maclean, D. J., Ebert, P. R., and Kazan, K. 2004. Antagonistic interaction between abscisic acid and jasmonateethylene signaling pathways modulates defense gene expression and disease resistance in Arabidopsis. Plant Cell 16:3460-3479.

3. Bassam, B. J., Caetano-Anolles, G., and Gresshoff, P. M. 1991. Fast and sensitive silver staining of DNA in polyacrylamide gels. Anal. Biochem. 196:80-83.

4. Bürglin, T. R. 1994. A comprehensive classification of homeobox genes. Pages 25-71 in: Guidebook to the Homeobox Genes. D. Duboule, ed. Oxford University Press, Oxford, UK.

5. Chan, R. L., Gago, G. M., Palena, C. M., and Gonzalez, D. H. 1998. Homeoboxes in plant development. Biochim. Biophys. Acta. 1442:1-19.

6. Coego, A., Ramirez, V., Gil, M., Flors, V., Mauch-Mani, B., and Vera, P. 2005. An Arabidopsis homeodomain transcription factor, OVEREXPRESSOR OF CATIONIC PEROXIDASE 3, mediates resistance to infection by necrotrophic pathogens. Plant Cell 17:2123-2137.

7. Gehring, W. J., Affolter, M., and Bürglin, T. 1994. Homeodomain proteins. Annu. Rev. Biochem. 63:487-526.

8. Gehring, W. F., Qian, Y. Q., Billeter, M., Furukubo-Tokunaga, K., Schier, A. F., Resendez-Perez, D., Affolter, M., Otting, G., and Wüthrich, K, 1994. Homeodomain-DNA recognition. Cell 78:211-223.

9. Griffey, C. A., and Das, M. K. 1994. Inheritance of adult-plant resistance to powdery mildew in Knox 62 and Massey winter wheats. Crop Sci. 34:641-646.

10. Gustafson, G. D., and Shaner, G. 1982. The influence of plant age on the expression of slow-mildewing resistance in wheat. Phytopathology 72:746-749.

11. Haecker, A., Gross-Hardt, R., Geiges, B., Sarkar, A., Breuninger, H., Herrmann, M., and Laux, T. 2004. Expression dynamics of WOX genes mark cell fate decisions during early embryonic patterning in Arabidopsis thaliana. Development 131:657-668.

12. Himmelbach, A., Hoffmann, T., Leube, M., Hohener, B., and Grill, E. 2002. Homeodomain protein ATHB6 is a target of the protein phosphatase ABI1 and regulates hormone responses in Arabidopsis. EMBO J. 21:3029-3038.

13. Huang, X. Q., and Röder, M. S. 2004. Molecular mapping of powdery mildew resistance genes in wheat: A review. Euphytica 137:203-223.

14. Johnson, R. 1988. Durable resistance to yellow (stripe) rust in wheat and its implications in plant breeding. Pages 63-75 in: Breeding Strategies for Resistance to the Rusts of Wheat. N. W. Simmonds and S. Rajaram, eds. CIMMYT Mexico.

15. Kang, Z. S., Huang, L. L., and Buchenauer, H. 2002. Ultrastructural changes and localization of lignin and callose in compatible and incompatible interactions between wheat and Puccinia striiformis. J. Plant Dis. Prot. 109:25-37.

16. Kang, Z. S., Wang, Y., Huang, L. L., Wei, G. R., and Zhao, J. 2003. Histology and ultrastructure of incompatible combination between Puccinia striiformis and wheat cultivars with low reaction type resistance. Sci. Agric. Sin. 2:1102-1113.

17. Kuraparthy, V., Chhuneja, P., Dhaliwal, H. S., Kaur, S., Bowden, R. L., and Gill, B. S. 2007. Characterization and mapping of cryptic alien introgression from Aegilops geniculata with new leaf rust and stripe rust resistance genes Lr57 and Yr40 in wheat. Theor. Appl. Genet. 114:13791389.

18. Liang, S. S., Suenaga, K., He, Z. H., Wang, Z. L., Liu, H. Y., Wang, D. S., Singh, R. P., Sourdile, P., and Xia, X. C. 2006. Quantitative trait loci 
mapping for adult-plant resistance to powdery mildew in bread wheat. Phytopathology 96:784-789.

19. Lin, F., and Chen, X. M. 2007. Genetics and molecular mapping of genes for race specific and all-stage resistance and non-specific hightemperature adult-plant resistance to stripe rust in spring wheat cultivar Alpowa. Theor. Appl. Genet. 114:1277-1287.

20. Lincoln, C., Long, J., Yamaguchi, J., Serikawa, K., and Hake, S. 1994. A knotted 1-like homeobox gene in Arabidopsis is expressed in the vegetative meristem and dramatically alters leaf morphology when overexpressed in transgenic plants. Plant Cell 6:1859-1876.

21. Liu, S. X., Griffey, C. A., and Saghai-Maroof, M. A. 2001. Identification of molecular markers associated with adult plant resistance to powdery mildew in common wheat cultivar Massey. Crop Sci. 41:1268-1275.

22. Livak, K. J., and Schmittgen, T. D. 2001. Analysis of relative gene expression data using realtime quantitative PCR and the $2^{-\Delta \Delta C}$ method. Methods 25:402-408.

23. Long, J. A., Moan, E. I., Medford, J. I., and Barton, M. K. 1996. A member of the KNOTTED class of homeodomain proteins encoded by the STM gene of Arabidopsis. Nature 379:66-69.

24. Lorenzo, O., Piqueras, R., Sanchez-Serrano, J. J., and Solano, R. 2003. ETHYLENE RESPONSE FACTOR 1 integrates signals from ethylene and jasmonate pathways in plant defense. Plant Cell 15:165-178.

25. Mayda, E., Tornero, P., Conejero, V., and Vera, P. 1999. A tomato homeobox gene (HD-Zip) is involved in limiting the spread of programmed cell death. Plant J. 20:591-600.

26. McIntosh, R. A., Devos, K. M., Dubcovsky, J., Morris, C. F., Appels, R., and Anderson, O. A. 2005. Catalogue of gene symbols for wheat: 2005 (suppl.) http://www.wheat.pw.usda.gov/GG2/pubs.shtml.

27. McIntosh, R. A., Devos, K. M., Dubcovsky, J., and Rogers, W. J. 2004. Catalogue of gene symbols for wheat: 2004 (suppl) http://www. wheat.pw.usda.gov/GG2/pubs.shtml.

28. McIntosh, R. A., Devos, K. M., Dubcovsky, J., Rogers, W. J., Morris, C. F., Appels, R., Somers, D. J., and Anderson, O. A. 2007. Catalogue of gene symbols: 2007 (suppl.) In: KOMUGI-Integrated Wheat Science Database. (http://www.grs.nig.ac.jp/wheat/komugi).

29. McIntosh, R. A., Wellings, C. R., and Park, R. F. 1995. Pages 1-200 in: Wheat Rusts: An Atlas of Resistance Genes. CSIRO Australia.

30. McIntosh, R. A., Yamazaki, Y., Devos, K. M., Dubcovsky, J., Rogers, W. J., and Appels, R. 2003. Catalogue of gene symbols for wheat. N. E. Pogna, M. Romano, E. A. Pogna, and G. Galterio, eds. Proc. 10th Int. Wheat Genet. Symp. Vol. 4:1-34.

31. Mondragon-Palomino, M., Meyers, B. C., Michelmore, R. W., and Gaut, B. S. 2002. Patterns of positive selection in the complete NBS-LRR gene family of Arabidopsis thaliana. Genome Res. 12:1305-1315.

32. Peterson, R. F., Campbell, A. B., and Hannah, A. E. 1948. A diagrammatic scale for estimating rust intensity of leaves and stems of cereals.
Can. J. Res. Sect. C. 26:496-500.

33. Ramburan, V. P., Pretorius, Z. A., Louw, J. H., Boyd, L. A., Smith, P. H., Boshoff, W. H. P., and Prins, R. 2004. A genetic analysis of adult plant resistance to stripe rust in the wheat cultivar Kariega. Theor. Appl. Genet. 108:1426-1433.

34. Reiser, L., Modrusan, Z., Margossian, L., Samach, A., Ohad, N., Haughn, G. W., and Fischer, R. L. 1995. The BEL1 gene encodes a homeodomain protein involved in pattern formation in the Arabidopsis ovule primordium. Cell 83:735-742.

35. Rosewarne, G. M., Singh, R. P., Huerta-Espino, J., William, H. M., Bouchet, S., Cloutier, S., McFadden, H., and Lagudah, E. S. 2006. Leaf tip necrosis, molecular markers and $\beta 1$-proteasome subunits associated with the slow rusting resistance genes Lr46/Yr29. Theor. Appl. Genet. 112:500-508.

36. Saghai-Maroof, M. A., Soliman, K. M., Jorgensen, R. A., and Allard, R. W. 1984 Ribosomal DNA spacer-length polymorphisms in barley: Mendelian inheritance, chromosomal location, and population dynamics. Proc. Natl. Acad. Sci. USA 81:8014-8018.

37. Singh, R. P. 1992. Genetic association of leaf rust resistance gene Lr34 with adult plant resistance to stripe rust in bread wheat. Phytopathology 82:835-838.

38. Singh, R. P., Nelson, J. C., and Sorrells, M. E. 2000. Mapping Yr28 and other genes for resistance to stripe rust in wheat. Crop Sci. 40:1148-1155.

39. Spielmeyer, W., McIntosh, R. A., Kolmer, J., and Lagudah, E. S. 2005. Powdery mildew resistance and Lr34/Yrl8 genes for durable resistance to leaf and stripe rust cosegregate at a locus on the short arm of chromosome 7D of wheat. Theor. Appl. Genet. 111:731-735.

40. Stubbs, R. W. 1988. Pathogenicity analysis of yellow (stripe) rust of wheat and its significance in a global context. Pages 23-28 in: Breeding Strategies for Resistance to the Rusts of Wheat. N. W. Simmonds and S. Rajaram, eds. CIMMYT Mexico.

41. Suenaga, K., Singh, R. P., Huerta-Espino, J., and William, H. M. 2003. Microsatellite markers for genes $\operatorname{Lr} 34 / \mathrm{Yr} 18$ and other quantitative trait loci for leaf rust and stripe rust resistance in bread wheat. Phytopathology 93:881-890.

42. Sun, Q., Wei, Y., Ni, C., Xie, C., and Yang, T. 2002. Microsatellite marker for yellow rust resistance gene $Y r 5$ introgressed from spelt wheat. Plant Breed. 121:539-541.

43. Suty, L., Lequeu, J., Lancon, A., Etienne, P., Petitot, A. S., and Blein, J. P. 2003. Preferential induction of $20 \mathrm{~S}$ proteasome subunits during elicitation of plant defense reactions: Towards the characterization of "plant defense proteasomes". Int. J. Biochem. Cell B. 35:637-650.

44. Xu, M. L., Huaracha, E., and Korban, S. S. 2001. Development of sequence-characterized amplified regions (SCARs) from amplified fragment length polymorphism (AFLP) markers tightly linked to the $V f$ gene in apple. Genome 44:63-70. 